\title{
Endothelial dysfunction in cerebral aneurysms
}

\author{
*Dallas L. Sheinberg, BS, David J. McCarthy, MSc, Omar Elwardany, MD, Jean-Paul Bryant, MSc, \\ Evan Luther, MD, Stephanie H. Chen, MD, John W. Thompson, PhD, and \\ Robert M. Starke, MD, MSc
}

Department of Neurosurgery, University of Miami, Florida

\begin{abstract}
Endothelial cell (EC) dysfunction is known to contribute to cerebral aneurysm (CA) pathogenesis. Evidence shows that damage or injury to the EC layer is the first event in CA formation. The mechanisms behind EC dysfunction in CA disease are interrelated and include hemodynamic stress, hazardous nitric oxide synthase (NOS) activity, oxidative stress, estrogen imbalance, and endothelial cell-to-cell junction compromise. Abnormal variations in hemodynamic stress incite pathological EC transformation and inflammatory zone formation, ultimately leading to destruction of the vascular wall and aneurysm dilation. Hemodynamic stress activates key molecular pathways that result in the upregulation of chemotactic cytokines and adhesion molecules, leading to inflammatory cell recruitment and infiltration. Concurrently, oxidative stress damages EC-to-EC junction proteins, resulting in interendothelial gap formation. This further promotes leukocyte traffic into the vessel wall and the release of matrix metalloproteinases, which propagates vascular remodeling and breakdown. Abnormal hemodynamic stress and inflammation also trigger adverse changes in NOS activity, altering proper EC mediation of vascular tone and the local inflammatory environment. Additionally, the vasoprotective hormone estrogen modulates gene expression that often suppresses these harmful processes. Crosstalk between these sophisticated pathways contributes to CA initiation, progression, and rupture. This review aims to outline the complex mechanisms of EC dysfunction in CA pathogenesis.
\end{abstract}

https://thejns.org/doi/abs/10.3171/2019.4.FOCUS19221

KEYWORDS endothelial cell dysfunction; cerebral aneurysm; inflammation; hemodynamic stress; reactive oxygen species; NOS

$\mathrm{C}$ EREBRAL aneurysms (CAs) have an estimated prevalence of $1 \%-3 \%$ and are responsible for $80 \%-85 \%$ of all spontaneous subarachnoid hemorrhages. ${ }^{28}$ CA formation and progression constitute a multifactorial disease process with dynamic contributions from genetic drivers, inflammatory reactions, and hemodynamic stress. ${ }^{69}$ There is substantial evidence showing that endothelial cell (EC) dysfunction plays a large role in CA pathogenesis, with damage or injury to the EC layer cited as the first event in CA formation. $24,30,31,44,50,62,66,67$ Through molecular crosstalk to vascular smooth muscle cells (VSMCs) and the intravascular lumen, ECs regulate vascular tone and local inflammatory reactions. Proper EC function is essential to vascular integrity through the regulation of VSMC proliferation, prevention of unnecessary platelet to vessel adhesion, and management of leukocyte recruitment. ${ }^{15} \mathrm{EC}$ expression and functionality is affected by their interactions with various lumen-based molecular and mechanical stimuli. ${ }^{31}$

EC dysfunction and damage is commonly reported in both in vivo and in vitro CA laboratory investigations. Histopathological and clinical observations of human CA pathogenesis have validated these laboratory findings. ${ }^{24,30 \text {, }}$ $31,44,50,62,66,67$ This review explores the literature in order to clearly delineate the contribution of EC dysfunction in CA disease.

\section{Endothelial Cells and Hemodynamic Stress}

Under physiologically normal conditions, there is a balance between the integrity of the vascular wall and the

ABBREVIATIONS CA = cerebral aneurysm; COX-2 = cyclooxygenase 2; $E C=$ endothelial cell; $E C-E C=E C$ to $E C ;$ eNOS = endothelial NOS; $E P_{2}=$ prostanoid receptor EP2; ER = estrogen receptor; ICAM-1 = intracellular adhesion molecule-1; IL-1 $\beta$ = interleukin 1 beta; iNOS = inducible NOS; JAG = juxta-apical groove; MCP-1 = monocyte

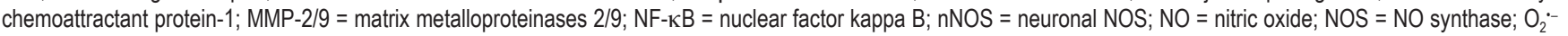
= superoxide; $\mathrm{ONOO}{ }^{-}$= peroxynitrite; $\mathrm{PGE}_{2}=$ prostaglandin $\mathrm{E} 2 ; \mathrm{PGI}_{2}=$ prostacyclin; $\mathrm{PKC} \zeta=$ protein kinase $\mathrm{C}$ zeta; $\mathrm{ROS}=$ reactive oxygen species; $\mathrm{SOD}-2$ = superoxide dismutase 2; TNF- $\alpha=$ tumor necrosis factor alpha; VCAM-1 = vascular cell adhesion molecule-1; VSMC = vascular smooth muscle cell; WSS = wall shear stress. SUBMITTED March 1, 2019. ACCEPTED April 10, 2019. INCLUDE WHEN CITING DOI: 10.3171/2019.4.FOCUS19221.

* D.L.S., D.J.M., and O.E. share first authorship. 
hemodynamic forces acting upon it. Current literature suggests that abnormal hemodynamic stress can incite pathogenic EC transformation that contributes to CA disease ${ }^{6,34,59}$ Intravascular hemodynamic stress is composed of two separate entities, fluid force vectors and blood pressure, which fundamentally translate into perpendicular transmural pressure, circumferential cyclic stretch, and wall shear stress (WSS) ${ }^{8,18,26}$ Both transmural pressure and cyclic stretch are derived from blood pressure, whereas WSS is a tangential force exerted by flow vectors. ${ }^{56}$

When examining hemodynamic force in CA disease, most of the literature focuses on the effect of WSS. Mathematically, WSS is the force that a fluid in motion exerts on the walls that surround it: ${ }^{35} \mathrm{WSS}=\mu(d x / d y)$, where $\mu$ is the dynamic viscosity of fluid, $x$ is the flow velocity parallel to the wall, and $y$ is the distance to the wall. Variations in the magnitude and duration of WSS have a significant effect on EC morphology and gene expression. ${ }^{9,41}$

Following the properties of fluid dynamics, blood flows within the vessels in either a laminar or turbulent manner. ${ }^{37}$ Laminar flow is unidirectional, consisting of parallel flow vectors that do not mix during fluid transport. Pulsatile laminar blood flow occurs within the vasculature under normal conditions..$^{10}$ Conversely, turbulent flow consists of nonuniform, chaotic, and volatile flow vectors. When blood encounters arterial branch points, the change in vessel angle results in an increased WSS at the bifurcation apex, with larger branching angles resulting in higher WSS magnitudes. In comparison, flow within an aneurysm dome is turbulent.$^{54}$ Normal laminar flow exerts medium WSS, whereas turbulent flow exerts low WSS because of less parallel fluid vectors. ${ }^{15}$ ECs respond differently when subjected to abnormal WSS magnitudes. ${ }^{10,15,19,42,54}$

Throughout the pulsatile cardiac cycle, cerebral ECs are subjected to an estimated WSS of 9.5-15 dyne $/ \mathrm{cm}^{2}$, with higher levels localized at the arterial bifurcation apex..$^{52,54}$ Because of the variation in WSS magnitude and duration, it has proven difficult to properly organize a cohesive EC WSS response profile. In addition to the deviations from normal WSS magnitude, there are acute and prolonged changes in WSS that affect ECs differently. Thus, in their review of hemodynamic stress in cerebral vascular disease, Nixon et al. organized the EC WSS response profiles according to prolonged and acute WSS. ${ }^{54}$ However, this organizational method fails to capture the different magnitudes of WSS utilized in the reviewed studies. In their review, some studies that were labeled as involving "high" WSS actually examined EC response under normal WSS conditions (approximately 10-12 dyne $/ \mathrm{cm}^{2}$ ). ${ }^{54}$ It is imperative to assess EC responses in three separate WSS magnitudes: normal, low (approximately $2-6 \mathrm{dyne} / \mathrm{cm}^{2}$ ), and high (> 14-15 dyne $\left./ \mathrm{cm}^{2}\right)$.

When subjected to normal WSS, ECs demonstrate healthy maintenance and proliferation through the suppression of cyclin-dependent kinase activity. ${ }^{2}$ Furthermore, they effectively balance the mTOR signaling cascade through dual activation of antimitotic AMPK and proliferative Akt. ${ }^{15}$ ECs exposed to prolonged normal WSS typically promote a low inflammatory environment through the downregulation of nuclear factor kappa B $(\mathrm{NF}-\mathrm{\kappa B})$ and epigenetic gene repression. ${ }^{22,42,71}$ With re- spect to cellular morphology, normal WSS ECs organize themselves into stretched, elongated rows that are oriented in the direction of flow, containing long parallel actin cytoskeletons.

In recent decades many investigators have shown that deviations from normal WSS contribute to various aspects of EC dysfunction in CA pathogenesis. . $^{11,24,50,54,60}$ Initially in CA models in rodents, Kondo et al. found that abnormally high WSS leads to CA formation. ${ }^{38}$ Building on this, Fukuda et al. observed that the initial stages of CA pathogenesis occurred at the vessel bifurcation intimal pad and the region distal to it, which they defined as the juxtaapical groove (JAG). ${ }^{24}$ They noted that these JAG regions were subjected to the highest magnitude of WSS and were associated with EC degenerative changes that ultimately led to CA formation. Given these morphological observations, they classified the early EC degenerative changes into five consecutive grades (Table 1). In later studies, Jamous et al. similarly observed that CA formation began with high WSS and EC injury in the "area just distal to the apical intimal pad," the same region Fukuda et al. defined as the JAG. ${ }^{30,31}$ Jamous et al. further studied CA formation at bifurcation sites, creating a 3 -stage classification system that delineated aneurysm formation and progression (Fig. 1). Stage I was characterized by abnormal EC morphological changes and loss of eNOS expression. Stage II was marked by inflammatory zone formation, which catalyzed proteolytic destruction of the vascular wall. Stage III embodied the clinical representation of CA disease, with saccular dilation.

More recently, Aoki et al. uncovered a molecular pathway for high WSS-induced endothelial degeneration. ${ }^{6}$ They demonstrated that initial high WSS (approximately 15 dyne $/ \mathrm{cm}^{2}$ ) induces an EC self-amplified loop of COX2-PGE $-\mathrm{EP}_{2}-\mathrm{NF}-\mathrm{\kappa B}$ (cyclooxygenase 2, prostaglandin $\mathrm{E} 2$, prostanoid receptor EP2, nuclear factor kappa B) that eventually leads to CA pathogenesis. In the middle of this pathway, the transcription factor NF- $\mathrm{BB}$ has a decisive role in aneurysm formation and progression. Specifically, it leads to increased expression of vascular cell adhesion molecule-1 (VCAM-1), intracellular adhesion molecule-1 (ICAM-1), and monocyte chemoattractant protein-1 (MCP-1), which are responsible for inflammatory cell adhesion and recruitment. Subsequent macrophage infiltration increases inflammatory cytokines (tumor necrosis factor alpha [TNF- $\alpha$ ], interleukin 1 beta [IL-1 $\beta]$ ) and matrix metalloproteinases (MMP-2/9), which propagate inflammatory response and the degradation of matrix proteins and apoptosis of smooth muscle cells (Jamous stage II). Furthermore, inhibition/knockout of $\mathrm{COX}-2$ or $\mathrm{EP}_{2}$ resulted in decreased $\mathrm{NF}-\kappa \mathrm{B}$ expression with a reduced incidence of CA formation. ${ }^{3}$

While high WSS contributes to CA formation, turbulent flow within the aneurysm dome exerts low WSS and contributes to growth and rupture. ECs subjected to low WSS appear round with short disorganized actin filaments and have high turnover rates with increased apoptotic activity via the protein kinase $\mathrm{C}$ zeta $(\mathrm{PKC} \xi)$ and p53 pathway. ${ }^{15,19,27}$ Furthermore, ECs exposed to low WSS have an increased expression of NF- $\kappa \mathrm{B}$, potentiating the already present macrophage infiltration. The combina- 
TABLE 1. Summary of CA formation stages and associated EC signaling pathways

\begin{tabular}{|c|c|c|c|}
\hline $\begin{array}{l}\text { Jamous et } \\
\text { al., } 2005\end{array}$ & $\begin{array}{l}\text { Fukuda et al., } \\
\qquad 2000\end{array}$ & Pathological Changes & Signaling Pathways \\
\hline \multirow{3}{*}{ Stage I } & Grade 1 & No damage & \multirow{3}{*}{$\begin{array}{l}\uparrow \mathrm{WSS} \rightarrow \uparrow \text { NADPH oxidase } \rightarrow \uparrow \text { ROS } \\
\uparrow \mathrm{COX}-2-\mathrm{PGE}_{2}-\mathrm{EP}_{2}-\mathrm{NF}-\mathrm{KB} \\
\uparrow \mathrm{MAP} \text { kinase } \rightarrow \downarrow \text { claudin, occludin } \\
\uparrow \mathrm{Ca}^{2+} \text {-calmodulin binding }+\mathrm{PKB} \rightarrow \uparrow \text { eNOS }\end{array}$} \\
\hline & Grade 3 & Moderate damage: some vacuoles in EC cytoplasm & \\
\hline & Grade 4 & $\begin{array}{l}\text { Severe damage: EC deformation w/ or w/o many vacuoles in } \\
\text { cytoplasm \& nucleus }\end{array}$ & \\
\hline
\end{tabular}

$\uparrow=$ increase $\downarrow \downarrow=$ decrease $\rightarrow=$ leads to; COX-2 = cyclooxygenase 2 ; eNOS = endothelial nitric oxide synthase; EP $_{2}=$ prostanoid receptor EP2; ICAM-1 = intracellular adhesion molecule-1; IFN- $\gamma$ = interferon gamma; IL = interleukin; iNOS = inducible NOS; MAP kinase = mitogen-activated protein kinase; MCP-1 = monocyte chemoattractant protein-1; MMP-2/9 = matrix metalloproteinases 2/9; NADPH oxidase = nicotinamide adenine dinucleotide phosphate oxidase; NF- $\mathrm{KB}=$ nuclear factor kappa $\mathrm{B} ; \mathrm{nNOS}=$ neuronal NOS; $\mathrm{PGE}_{2}=$ prostaglandin $\mathrm{E} 2 ; \mathrm{PKB}=$ protein kinase $\mathrm{B} ; \mathrm{PKC} \xi=$ protein kinase $\mathrm{C}$ zeta; $\mathrm{ROS}$ = reactive oxygen species; TAZ = transcriptional coactivator with a PDZ-binding motif (also known as WWTR1); TNF- $\alpha=$ tumor necrosis factor alpha; VCAM-1 = vascular cell adhesion molecule-1; YAP = Yes-associated protein.

These molecular pathways are not necessarily restricted to the above stages or grades. There is carryover between stages or grades throughout CA pathogenesis. Additionally, there is significant crosstalk between these pathways. For further information, refer to Fig. 1.

tion of increased EC apoptosis and macrophage MMP-9/ MMP-2 degradation of the extracellular matrix leads to vessel thinning and an elevated rupture risk in low-WSS regions, such as the dome tip. ${ }^{51,73}$ With recent advances in computational analysis, these laboratory findings are becoming clinically validated. In a computational analysis of 20 human middle cerebral artery aneurysms, Shojima et al. observed that the lowest WSS magnitude was often at the apex of the aneurysm, suggesting that high WSS may spur CA formation, while low WSS encourages CA progression. ${ }^{60}$ This finding was supported by Boussel and colleagues' discovery that low-WSS CA regions experience the most growth and by Skodvin and associates' recent observation that CAs with larger areas of low WSS are more likely to rupture. ${ }^{11,61}$

\section{Nitric Oxide Synthase}

Nitric oxide (NO) is a hydrophobic molecule with a short half-life, allowing for easy passage through neighboring cell membranes and a short-lived localized effect. ${ }^{32}$ It has several important roles in vascular physiology including tone modulation, inhibition of smooth muscle cell proliferation, suppression of proinflammatory mediators, and maintenance of proper EC function and integrity. ${ }^{7} \mathrm{NO}$ is synthesized by the nitric oxide synthase (NOS) family of enzymes, composed of the isoforms endothelial NOS (eNOS), located in ECs; inducible NOS (iNOS), located in macrophages and VSMCs; and neuronal NOS (nNOS), located in neurons. ${ }^{32}$ eNOS maintains normal blood pressure and hemodynamic stress through its baseline production of the vasodilator NO.48 The relationship between
NOS and CA pathogenesis has been frequently reported in the literature. $5,24,62$

While eNOS is primarily regulated through $\mathrm{Ca}^{2+}$-calmodulin binding, it can alternatively be activated by laminar WSS through protein kinase B phosphorylation. ${ }^{23,25} \mathrm{In}$ addition to upregulating eNOS activity, laminar WSS induces transient and prolonged eNOS mRNA transcription through c-Src-dependent pathways. ${ }^{20}$ When subjected to pathogenic low WSS, ECs fail to express eNOS. ${ }^{29}$ In contrast, acute or prolonged high WSS results in increased eNOS transcription and activation, which helps to prevent initial vessel injury (stage I of CA formation) through vasodilation. ${ }^{47}$ This vasodilation decreases WSS by increasing the distance to the vessel wall (see WSS equation above). Fukuda et al. supported this theory in CA models in the rat after observing that eNOS is upregulated at arterial bifurcation JAG points. ${ }^{24}$ This high WSS-induced eNOS expression is modulated by EC environments; for example, eNOS is decreased in hypoxia or hyperglycemia and increased by homocysteine. ${ }^{47}$ In rat CA tissue, however, eNOS expression was pathogenically decreased, suggesting that sometime during CA formation the endothelium loses the ability to effectively produce eNOS..$^{5,24}$ Despite this theory, Aoki et al. observed that $\mathrm{eNOS}^{-/}$knockout mice had the same CA prevalence as wild-type mice. Surprisingly, the eNOS knockout mice effectively protected against CA formation through a compensatory increase in nNOS expression, which sufficiently replaced prior eNOS NO production. ${ }^{5}$ However, nNOS compensation is not observed in clinical CA disease. This laboratory to clinical discrepancy is likely attributable to the inability of a genetic knockout model to replicate the inflammatory environment observed in CA pathogenesis. ${ }^{13,49}$ 


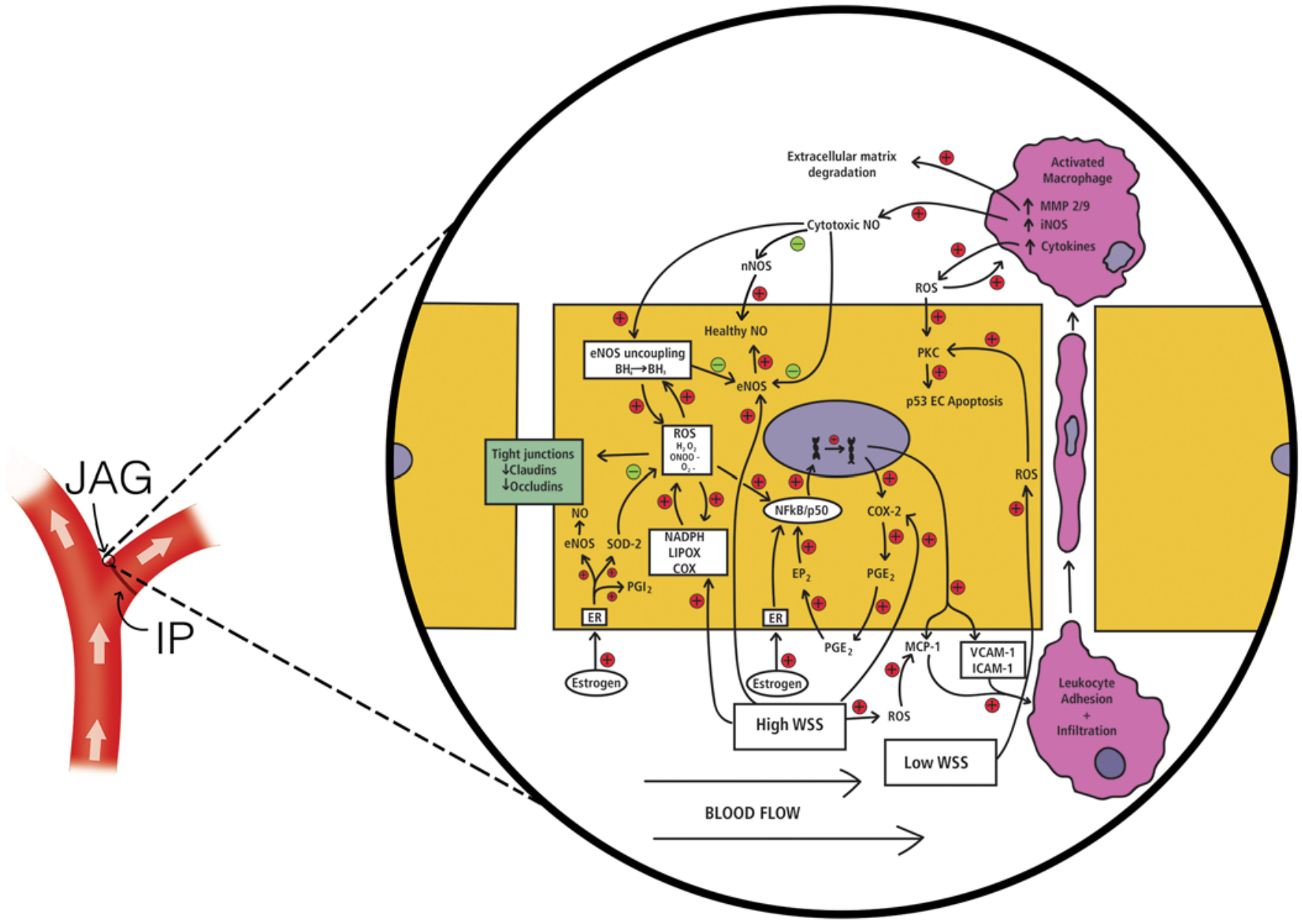

FIG. 1. Left: A macroscopic view of the primary site of CA pathogenesis at the vessel bifurcation. IP = intimal pad; JAG = juxtaapical groove. Right: A microscopic view of molecular signaling pathways occurring at the JAG leading to endothelial dysfunction. $\mathrm{BH}_{3}=$ trihydrobiopterin radical; $\mathrm{BH}_{4}=$ tetrahydrobiopterin; $\mathrm{COX}=$ cyclooxygenase; $\mathrm{EC}$ = endothelial cell; eNOS = endothelial nitric oxide synthase; $\mathrm{EP}_{2}=$ prostanoid receptor $E P 2 ; \mathrm{ER}=$ estrogen receptor; $\mathrm{H}_{2} \mathrm{O}_{2}=$ hydrogen peroxide; ICAM-1 = intracellular adhesion molecule-1; iNOS = inducible NOS; LIPOX = lipoxygenase; MCP-1 = monocyte chemoattractant protein-1; MMP-2/9 = matrix metalloproteinases 2/9; NADPH = nicotinamide adenine dinucleotide phosphate oxidase; NFkB = nuclear factor kappa $\mathrm{B}$; nNOS = neuronal NOS; $\mathrm{NO}$ = nitric oxide; $\mathrm{O}_{2}^{-}=$superoxide; $\mathrm{ONOO}^{-}=$peroxynitrite; $\mathrm{PGE}_{2}=$ prostaglandin $\mathrm{E} 2 ; \mathrm{PGI}_{2}=$ prostacyclin; $\mathrm{PKC}=$ protein kinase $\mathrm{C}$ zeta; $\mathrm{ROS}$ = reactive oxygen species; $\mathrm{SOD}-2$ = superoxide dismutase $2 ; \mathrm{VCAM}-1$ = vascular cell adhesion molecule-1. Copyright Roberto C. Suazo. Published with permission.

In CA formation, Jamous stage II is characterized by an increased inflammatory environment. ${ }^{30}$ While eNOS and nNOS exhibit CA protective effects, iNOS is expressed by macrophages and VSMC in abnormal conditions such as mechanical injury and inflammation. Increased iNOS expression has been observed in human CA tissue. ${ }^{24}$ iNOS activation and expression is calcium independent and is increased by reactive oxygen species (ROS) and inflammatory mediators such as IFN- $\gamma$, TNF- $\alpha$, and IL- $1 \beta .55$ Typically, the quantity of NO produced by eNOS is much less than that synthesized by iNOS, which generates large cytotoxic quantities of $\mathrm{NO}^{62}$ In a porcine cerebral artery model, iNOS induction was shown to impair eNOS and nNOS activity, partly through a negative NO feedback loop. ${ }^{13,49}$ The iNOS-mediated downregulation of eNOS and $\mathrm{nNOS}$ is likely why nNOS fails to compensate for eNOS loss in typical CA pathogenesis. ${ }^{5}$
Other than the iNOS inhibition, abnormal genetic or environmental eNOS activity has been shown to contribute to CA pathogenesis. Originally discovered to have a significant association with coronary vasospasm, the T-786C eNOS single nucleotide polymorphism (SNP) is a thymine (T) to cytosine (C) substitution at a locus 786 that may affect CA pathogenesis. Human ECs containing this eNOS SNP have significantly reduced eNOS activity. ${ }^{53}$ A metaanalysis suggested that the polymorphism was associated with an increased risk of CA incidence in Asian populations. ${ }^{72}$ In patients with ruptured aneurysms, Khurana et al. found that homozygous $\mathrm{C} / \mathrm{C}$ eNOS patients seemed to clinically present similar to $\mathrm{T} / \mathrm{T}$ patients, whereas a heterogeneous T/C eNOS genotype was independently associated with a larger $(>10 \mathrm{~mm})$ aneurysm size $(\mathrm{p}=0.03) .{ }^{36}$ However, a more rigorous investigation by Akagawa et al., which balanced the enrollment of Korean and Japanese CA 
patients, failed to find any association between CA size and the heterozygous genotype. ${ }^{1}$ To date, there remains no clear molecular explanation for why a homozygous $\mathrm{C} / \mathrm{C}$ mutant genotype might behave similar to a homozygous wild-type genotype, with $\mathrm{T} / \mathrm{C}$ heterozygotes demonstrating worse CA pathogenesis. In addition to genetically mutated eNOS, abnormal inflammatory environments or estrogen levels can dramatically alter eNOS functionality.

\section{Estrogen and Endothelial Dysfunction}

The steroid hormone estrogen has been shown to have antiinflammatory, antioxidant, and vasoprotective effects. ${ }^{14,70}$ In ECs and VSMCs, estrogen binds to cytosolic estrogen receptors alpha $(\mathrm{ER} \alpha)$ and beta $(\mathrm{ER} \beta)$. Upon binding to estrogen, the ER complex translocates into the nucleus to modify gene expression. Estrogen's vasoprotection is primarily attributable to its modulation of eNOS, elimination of ROS, and regulation of prostanoid metabolism.

Estrogen has multiple different pathways that upregulate both eNOS and nNOS. Stirone et al. demonstrated that estrogen-ER $\alpha$ binding in cerebral ECs leads to both a rapid and a prolonged increase in eNOS activity via PI3kinase/Akt and MAPK signaling pathways. ${ }^{14,63}$ In eNOSdeficient states, estrogen can initiate nNOS compensation, which helps to prevent CA formation. ${ }^{5,40}$ Furthermore, estrogen-deficient ECs downregulate eNOS expression, leading to increased CA pathogenesis. ${ }^{67}$ Estrogen-ER $\alpha$ binding also promotes vasoprotection through prostacyclin $\left(\mathrm{PGI}_{2}\right)$-mediated vasodilation. In rodent models, the administration of estradiol enhances $\mathrm{PGI}_{2}$ production via pathways involving COX-1 and $\mathrm{PGI}_{2}$ synthase. ${ }^{57}$

Interestingly, Tada et al. observed that ER $\beta$ agonists, but not $E R \alpha$ agonists or estradiol, significantly reduced the CA incidence in ovariectomized mice. ${ }^{64}$ This protective effect was negated after NOS inhibition and ER $\beta$ knockout, suggesting that the protective effect of estrogen-ER $\beta$ occurred through NO generation. These authors' findings challenge the role of estrogen-ER $\alpha$, a known regulator of eNOS, in CA disease. Further studies have suggested that estrogen-ER $\beta$ binding may help to prevent aneurysm rupture ${ }^{65}$ In ovariectomized mice, Xing et al. demonstrated that estrogen-ER $\beta$ activation decreased the expression of $\mathrm{NF}-\kappa \mathrm{B}$, a known CA inflammatory transcription factor. ${ }^{70}$ In a similar rodent model, Maekawa et al. demonstrated that treatment with the ER modulator bazedoxifene significantly decreased aneurysm rupture incidence from 52\% to $17 \%{ }^{46}$ Furthermore, bazedoxifene decreased levels of IL-1 $\beta$ and MMP-9 and restored basal mRNA levels of $E R \beta$ and $E R \alpha{ }^{48}$

Other studies have examined the effect of estrogen on oxidative stress, showing that each ER has a distinct role in the expression of superoxide dismutase 2 (SOD-2), an enzyme that aids in ROS elimination. ER $\alpha$ is responsible for increased SOD-2 activation, while ER $\beta$ regulates its basal expression. ${ }^{43}$ Estrogen also mediates the expression of NADPH oxidase, an enzyme that produces ROS. Estrogen-deficient states lead to a downregulation of SOD-2 and upregulation of NADPH oxidase, which results in oxidative stress and subsequent vascular injury.
The role of estrogen in CA pathogenesis has been clinically validated. In a meta-analysis of 68 studies, Vlak et al. reported an overall female/male unruptured aneurysm prevalence ratio of 1.57 , which rose to 2.2 among adults older than 50 years. ${ }^{68}$ This suggests an increased CA risk in postmenopausal estrogen-deficient women. Other investigations have significantly linked female sex to aneurysm formation (OR 4.73), one of which even cited it as the sole independent risk factor in elderly women (ages $70-84$ years)..$^{33,39}$

\section{Endothelial Cell-to-Cell Adhesions}

EC-to-EC (EC-EC) junctions are composed of tight junctions, adherens junctions, and PECAM-1 (CD31), which maintain vessel wall integrity and regulate paracellular transport. As previously discussed, abnormal WSS and iNOS activity lead to increased quantities of inflammatory cells (macrophages, B lymphocytes, T lymphocytes, and natural killer cells) in CA tissue. There is mounting evidence that EC-EC junction dysfunction significantly contributes to CA pathogenesis.

Tight junctions are constructed from occludins, claudins, and junctional adhesion molecules. Using scanning and transmission electron microscopes in rats, Tada et al. observed EC-EC junction morphological changes at arterial bifurcations in early aneurysm stages. ${ }^{66}$ Early endothelial damage consisted of interendothelial gap formation without obvious arterial wall depressions, coinciding with Jamous stage I. Gap formation was followed by leukocyte adhesion and migration into the paracellular space, coinciding with Jamous stage II. Further progression led to expansion of this defect resulting in outward bulging of the vessel wall, coinciding with Jamous stage III. Initial EC gap formation was associated with a reduction of the tight junction proteins occludin and ZO-1, with persistent normal expression of adherens junction proteins and PECAM-1. Thus, the EC degeneration observed in early CA disease is likely accompanied by interendothelial gap formation due to a pathological reduction in tight junction proteins ${ }^{21}$ Furthermore, the unaltered expression of PECAM-1 likely promotes leukocyte traffic through these interendothelial gaps, promoting a CA inflammatory environment.

ROS generation also contributes to interendothelial gap formation, cellular morphological change, and actin filament reorganization. ${ }^{44}$ Low WSS decreases the expression of occludins via a combination of ROS and MAPK signaling pathways. ${ }^{17}$ Ultimately, these cellular changes result in increased paracellular permeability and enhanced inflammatory cell infiltration.

\section{Oxidative Stress and Endothelial Cells}

There are multiple sources of oxidative stress that contribute to CA formation, progression, and rupture. Known CA risk factors that contribute to ROS generation include cigarette smoke, alcohol, and hypertension. In a prior review, we discussed the major pathways of oxidative stress in CA pathogenesis including atherosclerosis, hemodynamic stress, endothelial dysfunction, VSMC phenotypic modulation, vessel wall remodeling, and apoptotic cell 
death. ${ }^{62}$ These pathways differentially contribute to the formation of ROS, such as superoxide $\left(\mathrm{O}_{2}^{--}\right)$, hydrogen peroxide $\left(\mathrm{H}_{2} \mathrm{O}_{2}\right)$, and peroxynitrite (ONOO--).

The main enzymatic sources of ROS in the cerebral vasculature include COX-2, lipoxygenase, and NADPH oxidase. ${ }^{62}$ The latter is utilized by cerebral ECs, VSMCs, and macrophages to produce $\mathrm{O}_{2}{ }^{-}-$and $\mathrm{H}_{2} \mathrm{O}_{2}$ in response to growth factors, cytokines, and hemodynamic stress. In a positive feedback loop, free radicals propagate NADPH oxidase production of ROS. ${ }^{12}$ Similarly, the COX-2 pathway is a major source of $\mathrm{O}_{2}{ }^{--}$generation in response to IL-1 and TNF- $\alpha$. Other studies have demonstrated that cyclooxygenase and lipoxygenase pathways may be important sources of free radicals in CAs. ${ }^{62}$

Another potential source of ROS in the cerebral vasculature is NOS. While this primarily occurs through iNOS production of cytotoxic levels of $\mathrm{NO}$ and subsequent ONOO*- formation, ROS are also formed through eNOS uncoupling, where eNOS starts to produce $\mathrm{O}_{2}{ }^{-58}$. Though the mechanisms behind eNOS uncoupling are not entirely understood, popular theories include eNOS S-glutathionylation, L-arginine depletion, and eNOS cofactor $\mathrm{BH}_{4}$ oxidation to $\mathrm{BH}_{3} \cdot{ }^{23}$ Reversal of the above mechanisms through $\mathrm{BH}_{4}$ or L-arginine supplementation has been shown to restore EC function in common cardiovascular diseases such as hypercholesteremia, hypertension, and type 2 diabetes mellitus. However, the role of eNOS uncoupling in CA disease still needs elucidation.

Oxidative stress impairs the endothelial barrier by increasing EC permeability, enhancing leukocyte adhesion, and altering endothelial signal transduction and redoxregulated transcription factors. ${ }^{45}$ In response to oxidative stress, macrophage release of proinflammatory cytokines TNF- $\alpha$ and IL- $1 \alpha$ increases endothelial NF- $\kappa B$ via PKC and MAPK-dependent pathways. TNF- $\alpha$ also upregulates endothelial VCAM-1 expression through the transcriptional activators YAP/TAZ. ${ }^{16}$ As previously discussed, this leads to numerous CA potentiating effects, including increased leukocyte recruitment, adhesion, and infiltration. In an amplifying cycle, these newly recruited macrophages potentiate ROS production via NADPH oxidase, resulting in additional inflammatory cytokine production. This cycle is further fueled by ROS impairment of EC tight junction proteins, which increases leukocyte vessel infiltration. The free radical scavenger edaravone has been shown to inhibit CA formation in animal studies. ${ }^{4}$ The treatment of CA disease through ROS targeting offers a promising new opportunity for future bench to clinic translation.

Overall, these mechanisms of oxidative stress in CAs demonstrate a strong link among inflammation, hemodynamic stress, and aneurysm pathogenesis.

\section{Conclusions}

There is extensive laboratory and clinical evidence supporting the role of EC dysfunction in CA pathogenesis. The processes leading to this dysfunction are multifactorial and include hemodynamic stress, hazardous NOS activity, oxidative stress, estrogen imbalance, and EC-EC junction compromise. These interrelated pathways ultimately lead to EC dysfunction with ensuing CA initiation and progression. EC dysfunction is characterized by the loss of vasoprotective, antiinflammatory, antiatherogenic, and vasodilatory properties. Further investigation into the mechanisms of this complex process is essential to clearly elucidate CA pathogenesis and aid in the development of novel treatment modalities.

\section{Acknowledgments}

We would like to thank Roberto C. Suazo for his excellent work on our figure.

\section{References}

1. Akagawa H, Kasuya H, Onda H, Yoneyama T, Sasahara A, Kim CJ, et al: Influence of endothelial nitric oxide synthase T-786C single nucleotide polymorphism on aneurysm size. J Neurosurg 102:68-71, 2005

2. Akimoto S, Mitsumata M, Sasaguri T, Yoshida Y: Laminar shear stress inhibits vascular endothelial cell proliferation by inducing cyclin-dependent kinase inhibitor p21(Sdi1/Cip1/ Waf1). Circ Res 86:185-190, 2000

3. Aoki T, Kataoka H, Morimoto M, Nozaki K, Hashimoto N: Macrophage-derived matrix metalloproteinase-2 and -9 promote the progression of cerebral aneurysms in rats. Stroke 38:162-169, 2007

4. Aoki T, Nishimura M, Kataoka H, Ishibashi R, Nozaki K, Hashimoto N: Reactive oxygen species modulate growth of cerebral aneurysms: a study using the free radical scavenger edaravone and p47phox ${ }^{-1-}$ mice. Lab Invest 89:730-741, 2009

5. Aoki T, Nishimura M, Kataoka H, Ishibashi R, Nozaki K, Miyamoto S: Complementary inhibition of cerebral aneurysm formation by eNOS and nNOS. Lab Invest 91:619626, 2011

6. Aoki T, Nishimura M, Matsuoka T, Yamamoto K, Furuyashiki T, Kataoka $\mathrm{H}$, et al: $\mathrm{PGE}_{2}-\mathrm{EP}_{2}$ signalling in endothelium is activated by haemodynamic stress and induces cerebral aneurysm through an amplifying loop via NF- $\mathrm{KB}$. Br J Pharmacol 163:1237-1249, 2011

7. Arnal JF, Dinh-Xuan AT, Pueyo M, Darblade B, Rami J: Endothelium-derived nitric oxide and vascular physiology and pathology. Cell Mol Life Sci 55:1078-1087, 1999

8. Ballermann BJ, Dardik A, Eng E, Liu A: Shear stress and the endothelium. Kidney Int Suppl 67:S100-S108, 1998

9. Beckman JS, Beckman TW, Chen J, Marshall PA, Freeman BA: Apparent hydroxyl radical production by peroxynitrite: implications for endothelial injury from nitric oxide and superoxide. Proc Natl Acad Sci U S A 87:1620-1624, 1990

10. Berk BC: Atheroprotective signaling mechanisms activated by steady laminar flow in endothelial cells. Circulation 117:1082-1089, 2008

11. Boussel L, Rayz V, McCulloch C, Martin A, Acevedo-Bolton G, Lawton M, et al: Aneurysm growth occurs at region of low wall shear stress: patient-specific correlation of hemodynamics and growth in a longitudinal study. Stroke 39:29973002, 2008

12. Brandes RP, Kreuzer J: Vascular NADPH oxidases: molecular mechanisms of activation. Cardiovasc Res 65:16-27, 2005

13. Buga GM, Griscavage JM, Rogers NE, Ignarro LJ: Negative feedback regulation of endothelial cell function by nitric oxide. Circ Res 73:808-812, 1993

14. Chen Z, Yuhanna IS, Galcheva-Gargova Z, Karas RH, Mendelsohn ME, Shaul PW: Estrogen receptor alpha mediates the nongenomic activation of endothelial nitric oxide synthase by estrogen. J Clin Invest 103:401-406, 1999

15. Chiu JJ, Chien S: Effects of disturbed flow on vascular endo- 
thelium: pathophysiological basis and clinical perspectives. Physiol Rev 91:327-387, 2011

16. Choi HJ, Kim NE, Kim BM, Seo M, Heo JH: TNF- $\alpha-$ induced YAP/TAZ activity mediates leukocyte-endothelial adhesion by regulating VCAM1 expression in endothelial cells. Int J Mol Sci 19:E3428, 2018

17. Conklin BS, Vito RP, Chen C: Effect of low shear stress on permeability and occludin expression in porcine artery endothelial cells. World J Surg 31:733-743, 2007

18. Dardik A, Yamashita A, Aziz F, Asada H, Sumpio BE: Shear stress-stimulated endothelial cells induce smooth muscle cell chemotaxis via platelet-derived growth factor-BB and interleukin-1alpha. J Vasc Surg 41:321-331, 2005

19. Davies PF, Remuzzi A, Gordon EJ, Dewey CF Jr, Gimbrone MA Jr: Turbulent fluid shear stress induces vascular endothelial cell turnover in vitro. Proc Natl Acad Sci U S A 83:2114-2117, 1986

20. Davis ME, Cai H, Drummond GR, Harrison DG: Shear stress regulates endothelial nitric oxide synthase expression through c-Src by divergent signaling pathways. Circ Res 89:1073-1080, 2001

21. Dejana E, Orsenigo F, Molendini C, Baluk P, McDonald DM: Organization and signaling of endothelial cell-to-cell junctions in various regions of the blood and lymphatic vascular trees. Cell Tissue Res 335:17-25, 2009

22. Eng E, Ballermann BJ: Diminished NF-kappaB activation and PDGF-B expression in glomerular endothelial cells subjected to chronic shear stress. Microvasc Res 65:137-144, 2003

23. Förstermann U, Sessa WC: Nitric oxide synthases: regulation and function. Eur Heart J 33:829-837, 837a-837d, 2012

24. Fukuda S, Hashimoto N, Naritomi H, Nagata I, Nozaki K, Kondo S, et al: Prevention of rat cerebral aneurysm formation by inhibition of nitric oxide synthase. Circulation 101:25322538,2000

25. Fulton D, Gratton JP, McCabe TJ, Fontana J, Fujio Y, Walsh $\mathrm{K}$, et al: Regulation of endothelium-derived nitric oxide production by the protein kinase Akt. Nature 399:597-601, 1999

26. Gaucher C, Devaux C, Boura C, Lacolley P, Stoltz JF, Menu $\mathrm{P}$ : In vitro impact of physiological shear stress on endothelial cells gene expression profile. Clin Hemorheol Microcirc 37:99-107, 2007

27. Heo KS, Lee H, Nigro P, Thomas T, Le NT, Chang E, et al: PKC $\zeta$ mediates disturbed flow-induced endothelial apoptosis via p53 SUMOylation. J Cell Biol 193:867-884, 2011

28. Hitchcock E, Gibson WT: A review of the genetics of intracranial berry aneurysms and implications for genetic counseling. J Genet Couns 26:21-31, 2017

29. Hwang J, Ing MH, Salazar A, Lassègue B, Griendling K, Navab M, et al: Pulsatile versus oscillatory shear stress regulates NADPH oxidase subunit expression: implication for native LDL oxidation. Circ Res 93:1225-1232, 2003

30. Jamous MA, Nagahiro S, Kitazato KT, Satoh K, Satomi $\mathrm{J}$ : Vascular corrosion casts mirroring early morphological changes that lead to the formation of saccular cerebral aneurysm: an experimental study in rats. J Neurosurg 102:532535,2005

31. Jamous MA, Nagahiro S, Kitazato KT, Tamura T, Aziz HA, Shono M, et al: Endothelial injury and inflammatory response induced by hemodynamic changes preceding intracranial aneurysm formation: experimental study in rats. $\mathbf{J}$ Neurosurg 107:405-411, 2007

32. Jin RC, Loscalzo J: Vascular nitric oxide: formation and function. J Blood Med 2010:147-162, 2010

33. Juvela S, Poussa K, Porras M: Factors affecting formation and growth of intracranial aneurysms: a long-term follow-up study. Stroke 32:485-491, 2001

34. Kadirvel R, Ding YH, Dai D, Zakaria H, Robertson AM,
Danielson MA, et al: The influence of hemodynamic forces on biomarkers in the walls of elastase-induced aneurysms in rabbits. Neuroradiology 49:1041-1053, 2007

35. Katritsis D, Kaiktsis L, Chaniotis A, Pantos J, Efstathopoulos EP, Marmarelis V: Wall shear stress: theoretical considerations and methods of measurement. Prog Cardiovasc Dis 49:307-329, 2007

36. Khurana VG, Sohni YR, Mangrum WI, McClelland RL, O'Kane DJ, Meyer FB, et al: Endothelial nitric oxide synthase T-786C single nucleotide polymorphism: a putative genetic marker differentiating small versus large ruptured intracranial aneurysms. Stroke 34:2555-2559, 2003

37. Kleinstreuer C: Biofluid Dynamics: Principles and Selected Applications. Boca Raton, FL: CRC Press, 2016

38. Kondo S, Hashimoto N, Kikuchi H, Hazama F, Nagata I, Kataoka H: Cerebral aneurysms arising at nonbranching sites. An experimental study. Stroke 28:398-404, 1997

39. Kubo Y, Koji T, Kashimura H, Otawara Y, Ogawa A, Ogasawara K: Female sex as a risk factor for the growth of asymptomatic unruptured cerebral saccular aneurysms in elderly patients. J Neurosurg 121:599-604, 2014

40. Kuhlencordt PJ, Hötten S, Schödel J, Rützel S, Hu K, Widder J, et al: Atheroprotective effects of neuronal nitric oxide synthase in apolipoprotein E knockout mice. Arterioscler Thromb Vasc Biol 26:1539-1544, 2006

41. Li YS, Haga JH, Chien S: Molecular basis of the effects of shear stress on vascular endothelial cells. J Biomech 38:1949-1971, 2005

42. Lin K, Hsu PP, Chen BP, Yuan S, Usami S, Shyy JY, et al: Molecular mechanism of endothelial growth arrest by laminar shear stress. Proc Natl Acad Sci U S A 97:9385-9389, 2000

43. Liu Z, Gou Y, Zhang H, Zuo H, Zhang H, Liu Z, et al: Estradiol improves cardiovascular function through up-regulation of SOD2 on vascular wall. Redox Biol 3:88-99, 2014

44. Lum H, Malik AB: Regulation of vascular endothelial barrier function. Am J Physiol 267:L223-L241, 1994

45. Lum H, Roebuck KA: Oxidant stress and endothelial cell dysfunction. Am J Physiol Cell Physiol 280:C719-C741, 2001

46. Maekawa H, Tada Y, Yagi K, Miyamoto T, Kitazato KT, Korai M, et al: Bazedoxifene, a selective estrogen receptor modulator, reduces cerebral aneurysm rupture in ovariectomized rats. J Neuroinflammation 14:197, 2017

47. Malek AM, Izumo S, Alper SL: Modulation by pathophysiological stimuli of the shear stress-induced up-regulation of endothelial nitric oxide synthase expression in endothelial cells. Neurosurgery 45:334-345, 1999

48. Malek AM, Jiang L, Lee I, Sessa WC, Izumo S, Alper SL: Induction of nitric oxide synthase mRNA by shear stress requires intracellular calcium and G-protein signals and is modulated by PI 3 kinase. Biochem Biophys Res Commun 254:231-242, 1999

49. Mathewson AM, Wadsworth RM: Induction of iNOS restricts functional activity of both eNOS and nNOS in pig cerebral artery. Nitric Oxide 11:331-339, 2004

50. Meng H, Wang Z, Hoi Y, Gao L, Metaxa E, Swartz DD, et al: Complex hemodynamics at the apex of an arterial bifurcation induces vascular remodeling resembling cerebral aneurysm initiation. Stroke 38:1924-1931, 2007

51. Mohan S, Mohan N, Sprague EA: Differential activation of NF-kappa B in human aortic endothelial cells conditioned to specific flow environments. Am J Physiol 273:C572-C578, 1997

52. Nakatani H, Hashimoto N, Kang Y, Yamazoe N, Kikuchi $\mathrm{H}$, Yamaguchi S, et al: Cerebral blood flow patterns at major vessel bifurcations and aneurysms in rats. J Neurosurg 74:258-262, 1991

53. Nakayama M, Yasue H, Yoshimura M, Shimasaki Y, Kugiya- 
ma $\mathrm{K}$, Ogawa $\mathrm{H}$, et al: $\mathrm{T}-786 \rightarrow \mathrm{C}$ mutation in the 5 '-flanking region of the endothelial nitric oxide synthase gene is associated with coronary spasm. Circulation 99:2864-2870, 1999

54. Nixon AM, Gunel M, Sumpio BE: The critical role of hemodynamics in the development of cerebral vascular disease. J Neurosurg 112:1240-1253, 2010

55. Nunokawa Y, Ishida N, Tanaka S: Promoter analysis of human inducible nitric oxide synthase gene associated with cardiovascular homeostasis. Biochem Biophys Res Commun 200:802-807, 1994

56. Okada M, Matsumori A, Ono K, Furukawa Y, Shioi T, Iwasaki A, et al: Cyclic stretch upregulates production of interleukin-8 and monocyte chemotactic and activating factor/ monocyte chemoattractant protein-1 in human endothelial cells. Arterioscler Thromb Vasc Biol 18:894-901, 1998

57. Ospina JA, Krause DN, Duckles SP: 17beta-estradiol increases rat cerebrovascular prostacyclin synthesis by elevating cyclooxygenase-1 and prostacyclin synthase. Stroke 33:600-605, 2002

58. Radi R, Beckman JS, Bush KM, Freeman BA: Peroxynitrite oxidation of sulfhydryls. The cytotoxic potential of superoxide and nitric oxide. J Biol Chem 266:4244-4250, 1991

59. Sakamoto N, Saito N, Han X, Ohashi T, Sato M: Effect of spatial gradient in fluid shear stress on morphological changes in endothelial cells in response to flow. Biochem Biophys Res Commun 395:264-269, 2010

60. Shojima M, Oshima M, Takagi K, Torii R, Hayakawa M, Katada K, et al: Magnitude and role of wall shear stress on cerebral aneurysm: computational fluid dynamic study of 20 middle cerebral artery aneurysms. Stroke 35:2500-2505, 2004

61. Skodvin TØ, Evju Ø, Helland CA, Isaksen JG: Rupture prediction of intracranial aneurysms: a nationwide matched case-control study of hemodynamics at the time of diagnosis. J Neurosurg 129:854-860, 2018

62. Starke RM, Chalouhi N, Ali MS, Jabbour PM, Tjoumakaris SI, Gonzalez LF, et al: The role of oxidative stress in cerebral aneurysm formation and rupture. Curr Neurovasc Res 10:247-255, 2013

63. Stirone C, Boroujerdi A, Duckles SP, Krause DN: Estrogen receptor activation of phosphoinositide-3 kinase, akt, and nitric oxide signaling in cerebral blood vessels: rapid and long-term effects. Mol Pharmacol 67:105-113, 2005

64. Tada Y, Makino H, Furukawa H, Shimada K, Wada K, Liang EI, et al: Roles of estrogen in the formation of intracranial aneurysms in ovariectomized female mice. Neurosurgery 75:690-695, 2014

65. Tada Y, Wada K, Shimada K, Makino H, Liang EI, Murakami S, et al: Estrogen protects against intracranial aneurysm rupture in ovariectomized mice. Hypertension 63:1339_ 1344, 2014

66. Tada Y, Yagi K, Kitazato KT, Tamura T, Kinouchi T, Shimada K, et al: Reduction of endothelial tight junction proteins is related to cerebral aneurysm formation in rats. J Hypertens 28:1883-1891, 2010

67. Tamura T, Jamous MA, Kitazato KT, Yagi K, Tada Y, Uno M, et al: Endothelial damage due to impaired nitric oxide bioavailability triggers cerebral aneurysm formation in female rats. J Hypertens 27:1284-1292, 2009

68. Vlak MH, Algra A, Brandenburg R, Rinkel GJ: Prevalence of unruptured intracranial aneurysms, with emphasis on sex, age, comorbidity, country, and time period: a systematic review and meta-analysis. Lancet Neurol 10:626-636, 2011

69. Wiebers DO, Whisnant JP, Huston J III, Meissner I, Brown RD Jr, Piepgras DG, et al: Unruptured intracranial aneurysms: natural history, clinical outcome, and risks of surgical and endovascular treatment. Lancet 362:103-110, 2003

70. Xing D, Nozell S, Chen YF, Hage F, Oparil S: Estrogen and mechanisms of vascular protection. Arterioscler Thromb Vasc Biol 29:289-295, 2009

71. Xu S, Xu Y, Yin M, Zhang S, Liu P, Koroleva M, et al: Flowdependent epigenetic regulation of IGFBP5 expression by $\mathrm{H} 3 \mathrm{~K} 27 \mathrm{me} 3$ contributes to endothelial anti-inflammatory effects. Theranostics 8:3007-3021, 2018

72. Yang C, Qi ZY, Shao C, Xing WK, Wang Z: Association between three eNOS polymorphisms and intracranial aneurysms risk: a meta-analysis. Medicine (Baltimore) 94:e452, 2015

73. Zhou G, Zhu Y, Yin Y, Su M, Li M: Association of wall shear stress with intracranial aneurysm rupture: systematic review and meta-analysis. Sci Rep 7:5331, 2017

\section{Disclosures}

The authors report no conflict of interest concerning the materials or methods used in this study or the findings specified in this paper.

\section{Author Contributions}

Conception and design: Sheinberg, McCarthy, Elwardany, Bryant, Luther, Thompson, Starke. Acquisition of data: Sheinberg, McCarthy, Elwardany, Bryant, Luther, Thompson, Starke. Analysis and interpretation of data: Sheinberg, McCarthy, Elwardany, Bryant, Luther, Thompson, Starke. Drafting the article: Sheinberg, McCarthy, Elwardany, Bryant, Luther, Chen, Thompson. Critically revising the article: all authors. Reviewed submitted version of manuscript: all authors. Approved the final version of the manuscript on behalf of all authors: Sheinberg.

\section{Correspondence}

Dallas L. Sheinberg: University of Miami Miller School of Medicine, Miami, FL.dls226@med.miami.edu. 